\title{
Prognostic significance of Intracerebral Hemorrhage Score in predicting 30-day mortality in Chittagong Medical College Hospital
}

\author{
EMRAN MS ${ }^{1}$, HASSANUZZAMAN M ${ }^{2}$, MAJUMDER $\mathrm{S}^{3}$, ISLAM MRT, KABIR MHU, SIKDER ABMNHV, \\ MAJUMDER PW, UDDIN SAX, RUBEL MY, RAHMAN MW' ${ }^{10}, \mathrm{CHOWDHURY} \mathrm{MAA}^{11}$, \\ KHAN MA ${ }^{12}$, SARKER MHK ${ }^{13}$, CHOWDHURY A ${ }^{14}$
}

\begin{abstract}
:
Background:Prognosticating the outcome of Intracerebral Hemorrhage (ICH) at the time of admission is important to customize treatment in a cost-effective manner in such cases. ICH sore is a widely used prognosticating tool but yet not evaluated in our setting. This study was aimed to assess the prognostic factors influencing outcome and validating the $\mathrm{ICH}$ score for prediction of 30-day mortalityin hospitalized patients with $\mathrm{ICH}$. Materials and methods:This prospective observational study was conducted in Chittagong Medical College Hospital, Bangladesh among 105 consecutively admitted patients aged 18 years and above with a computed tomography evidence of spontaneous $\mathrm{ICH}$. ICH score was calculated soon after confirmation of diagnosis. Primary outcome measure was 30-day mortality after admission. Modified Rankin Scale (mRS) was used to assess outcome at discharge and at 30-day follow up. Results:A total of 104 patients were analyzed. Mean age of this cohort was $59.30 \pm 19.91$ years. At 30 days all 27 patients with an ICH score of 0 survived, whereas those having scores of 1, 2, 3, and 4 had 5.9\%, 33.3\%, 46.2\% and $88.9 \%$ mortality, respectively. ICH score was good for discriminating 30-day mortality with having an area under the ROC curve of 0.886 (95\% Cl:0.816-0.956; $p<0.001]$. For patients scoring above 2, the rate of poor functional outcome ( $m R S$ score $e$ "4) approaches 100\%. On the other hand, 18.5\% of patients with score of 0 and $64.7 \%$ of patients with a score of 1 are not functionally independent after 30 days. Conclusion:In conclusion, the present study has demonstrated that the $\mathrm{ICH}$ score is a strong prognostic indicator of $\mathrm{ICH}$ outcomes (30-day mortality and 30day functional outcome) among hospitalized patients in Bangladesh.
\end{abstract}

Key words:Intracerebral Hemorrhage; Intracerebral Hemorrhage Score; Prognosis; Bangladesh.

\section{Background:}

Intracerebral hemorrhage $(\mathrm{ICH})$ is the second most common cause of stroke and accounts for $10-20 \%$ of all strokes ${ }^{1,2}$. The incidence of $\mathrm{ICH}$ is increasing over the years ${ }^{3}$ and $\mathrm{ICH}$ remains the most dreadful among stroke subtypes with a 30-day mortality of $40 \%-50 \%{ }^{4}$. Though the exact scenario of Bangladesh is not known due to scarcity of

1. Dr. Md. Shawkat Emran, Resident, Department of Neurology, Chittagong Medical College, Chattogram, Bangladesh. Email: dr.emran13comc@gmail.com

2. Dr. Md. Hassanuzzaman,Professor and Head, Department of Neurology, Chittagong Medical College\& Hospital, Chattogram.

3. Dr. ShiulyMajumder,Associate Professor, Department of Neurology, Chittagong Medical College\& HospitalChattogram.

4. Dr. Md. Rafiqul Islam, Professor, Department of Neurology, Bangabandhu Sheikh Mujib Medical University (BSMMU), Dhaka.

5. Dr. Md. HumayunKabir,Neurologist, Chittagong Medical College Hospital.

6. Dr. Abu Bakar Muhammad NizamulHoqueSikder, Resident, Department of Neurology, Chittagong Medical College.

7. Dr. PijushMajumder, Registrar, Department of Neurology, Chittagong Medical College Hospital.

8. Dr. Syed ArifUddin, Resident, Department of Neurology, Chittagong Medical College.

9. Dr. Md. Rubel, Resident, Department of Neurology, Chittagong Medical College.

10. Dr. Md. WahidurRahman, Resident, Department of Neurology, Chittagong Medical College.

11. Dr. Mohammad AnwarulAzimChowdhury, Resident, Department of Neurology, Chittagong Medical College.

12. Dr. Md. Ashrafuzzaman Khan, Neurologist, National Institute of Neurosciences \& Hospital (NINS\&H), Dhaka.

13. Dr. Md. HumayunKabirSarker, Resident, Department of Neurology, Dhaka Medical College.

14. Dr. Ashish Chowdhury, Resident, Department of Neurology, Bangabandhu Sheikh Mujib Medical University (BSMMU). 
published literature it can be assumed that, the incidence of $\mathrm{ICH}$ is higher in comparison to the western population ${ }^{1,5}$, and the population at risk is younger compared to the western developed world ${ }^{6}$. Considering the poor long-term outcome for spontaneous $\mathrm{ICH}$ patients, an effective prognosticating scale is important to optimize the management plan for careful use of available resources, especially in low to middle income countries $^{7}$. The $\mathrm{ICH}$ score is one of the simple and functional methods in this regards. It is determined as the sum of specific point values for each of the five characteristics (GCS score, age e" 80 years, $\mathrm{ICH}$ volume, presence of $\mathrm{IVH}$, and infratentorial origin), with weighting of potential points for each characteristic based on strength of outcome association ${ }^{8}$.

However, for wider applicability of a riskstratification scale, such as the ICH score, it must be useful outside the cohort of patients from which it was developed. So, external validation to determine whether the $\mathrm{ICH}$ score could accurately risk-stratify patients in a cohort independent of that from which it was developed was done in different population. Till date several studies in abroad have shown the external validity of $\mathrm{ICH}$ score but the study population and the hospital settings were completely different from ours ${ }^{6,9-14}$. Published study on $\mathrm{ICH}$ score in Bangladesh is very limited and the external validity of $\mathrm{ICH}$ score is not aimed in any study yet. So, it is necessary to prove its efficacy as a predictor of adverse outcome of $\mathrm{ICH}$ in Bangladeshi population.

Contemplating this background, this study was planned to evaluate the role of $\mathrm{ICH}$ score in predicting 30-day mortality in patients with $\mathrm{ICH}$ presenting and getting admitted in a tertiary care hospital of Bangladesh.

\section{Materials and methods:}

This prospective observational study was performed in Chittagong Medical College Hospital, Chattogram, Bangladesh. It is a 1313 bedded tertiary care hospital and one of the largest hospitals in Bangladesh. Patients with $\mathrm{ICH}$ are usually admitted in different Medicine, Neurology and Neurosurgery wards of this hospital.
All patients with a computed tomography (CT) evidence of spontaneous $\mathrm{ICH}$ above the age of 18 years were included in this study. Patients or attendantswho denied formal consent, patients with coagulation abnormalities, aneurysmal hematomas, and vascular malformations, past history of stroke, patients having $\mathrm{ICH}$ secondary to a brain tumor or trauma, patients with a past history of stroke and patients who were undergone surgical procedure were excluded.

Sample size was determined for the comparison of the area under a Receiver Operating Characteristics Curve (ROC) curve. A sample of 71 patients would suffice for a $90 \%$ power to detect a difference of 0.3 between the area under the curve (AUC), under the null hypothesis of $A \cup C=$ 0.5 (no diagnostic accuracy) and the alternative hypothesis of AUC $=0.8$ (moderate diagnostic accuracy), at a significance level of 0.05 . However, considering the lost to follow up and to further increase the power of the study finally 105 patients were included in the study

Patients with a suspected diagnosis of acute stroke were subjected to an urgent noncontrast CT scan of the brain as soon as possible. Soon after, those diagnosed as $\mathrm{ICH}$ was enrolled and physically examined along with an evaluation for $\mathrm{ICH}$ scores. The scores used for 30-day mortality prediction was based on the ûrst evaluation after the enrollment. The data of the study subjects was collected by oral questionnaire regarding age, sex, education level, and risk factors for $\mathrm{ICH}$ (hypertension, diabetes, alcoholism, smoking, and anticoagulant and antiplatelet medications). Pulse, blood pressure (BP), respiratory rate, temperature, and GCS score was noted on admission. Hypertension and diabetes was diagnosed as having a previous diagnosis of these conditions by a registered physician or patients on anti-hypertensive or anti diabetic medications. Smoking was defined ever or never smokers. Obesity was defined as waist circumference $>90 \mathrm{~cm}$ in males and $>80 \mathrm{~cm}$ in females. Poor functional outcome was defined as mRS score e" 4 at 30 days.As it was an observational study, the treatment protocol of the patient had not been interrupted and he/she had got the treatment as per available hospital protocol. 
Patients of the study were monitored until discharge or death to observe the outcome. For those who had died within 30 days during the hospital stay, the cause of death was documented from the case record files. Those who was discharged before 30 days, a follow-up visit was arranged after 30 days of admission. Some patients who failed to attend the follow-up visit, telephonic follow-up was done.Primary outcome was defined as mortality assessment at 30-day after $\mathrm{ICH}$. A patient who survived and discharged was followed up in the outpatient department and over telephone regarding their final outcome.

Continuous data were expressed as mean \pm standard deviation (SD) and categorical variables were presented as percentages or proportions. The entire cohort was divided into survivor and nonsurvivor groups. Between these two groups, continuous and categorical variables were analyzed. Student's t-test was used to analyze continuous variableswhile categorical variables were compared by means of Chi-square test. Multivariate analysis, with the 30 day mortality as dependent variable, on variables found to be significant by univariate analysis, was performed finally. The discriminatory values of $\mathrm{ICH}$ score for predicting 30-day mortality was studied using ROC curve analyses with calculation of AUC. $p<0.05$ was considered statistically significant. Statistical analysis was performed using SPSS version 23.0.

Informed consent was obtained from competent patients before enrollment. In patients who were unable to give fully informed consent, assent was obtained from a legal representative. The study protocol was approved by the Ethical Review Committee of Chittagong Medical College (Memo number: CMC/PG/2019/543) on June 20, 2019.

\section{Results:}

Out of 105 enrolled patients one was lost to follow up and rest 104 were included in the final analysis. Out of 104 patients 81 patients survived and rest 23 died in 30 days following enrollment. Overall, the mean age of the study subjects was 59.3 years and there was female predominance. In univariate analysis, mean age $(p=0.04)$ but not the age group of e" 80 years was significantly associated with 30 days mortality. (Table I). Majority of the patients were hypertensive (76\%) and about half of them were obese $(49 \%)$. However, DM, IHD alcohol drinking habit, smoking and tobacco leaf use was present in $16.3 \%, 19 \%, 1.9 \%, 36.5 \%$ and $27.9 \%$ respectively. There was no association of these factors with 30-day mortality. The frequency of IVH, hydrocephalus and hemorrhage with a volume of $30 \mathrm{cc}$ or higher were significantly higher among the subjects who died $(p<0.05)$. Those who survived had a higher GCS than those who died, the difference being statistically significant $(p<0.001)$.In this cohort only $8.7 \%$ patients had infratentorial $\mathrm{ICH}$ and it was not associated with 30-days mortality (Table I.

In this cohort of 104 patients with $\mathrm{ICH}, 34$ (32.7\%) patients had $\mathrm{ICH}$ score 1 . No patients had $\mathrm{ICH}$ score 5 and above (Table II). Present study demonstrated that, 30-day mortality increases as $\mathrm{ICH}$ Score increases. No patient with an ICH Score of 0 died. Majority of patients $(88.9 \%, 8 / 9)$ with an $\mathrm{ICH}$ Score of 4 died. The 30-day case fatality for the entire cohort was $22.1 \%(23 / 104 ; 95 \% \mathrm{Cl}$, $14.13 \%-30.07 \%)$.

Figure 1 contrasts the "observed mortality" vs "expected mortality" as predicted by the $\mathrm{ICH}$ Score. Mortality increased with $\mathrm{ICH}$ score, but not to the extent previously reported. In particular, the largest discrepancy between observed and expected mortality was demonstrated among patients with $\mathrm{ICH}$ Scores of $3(46 \%$ vs $72 \%, \mathrm{P}<0.01)$.

The areas under ROC curve for the $\mathrm{ICH}$ score was 0.886 (95\% Cl: 0.816-0.956; $p<0.001$ ) (Figure 2). The ROC suggested a sensitivity of $90 \%$ at cutoff value of 3 with specificity of $71 \%$.

In the present cohort, ICH score was found to be predictive of poor functional outcome (mRS score $\geq 4$ ) at 30 days after discharge. From Figure 6 it is apparent that for all patients scoring above 2 , the rate of poor functional outcome approaches $100 \%$. On the other hand, $18.5 \%$ of patients with score of 0 and $64.7 \%$ of patients with a score of 1 are not independent after 30 days.

Variables that had a $p$ value of $<0.05$ in univariate analysis were selected for the multivariate regression analysis (Table 3 ). GCS score, the 
Table-I

Socio-demographic variables of the 104 patients with ICH and association of 30-day mortality with these variables

\begin{tabular}{|c|c|c|c|c|}
\hline Variables & $\begin{array}{c}\text { Total } \\
(n=104)\end{array}$ & $\begin{array}{c}\text { Survival } \\
(n=81)\end{array}$ & $\begin{array}{l}\text { Death } \\
(n=23)\end{array}$ & $p$ value \\
\hline \multicolumn{5}{|l|}{ Age (years) } \\
\hline$<80$ & $93(89.4 \%)$ & $75(80.6 \%)$ & $18(19.4 \%)$ & \multirow[t]{2}{*}{$0.063^{*}$} \\
\hline$\geq 80$ & $11(10.6 \%)$ & $6(54.5 \%)$ & $5(45.5 \%)$ & \\
\hline Mean $\pm S D$ & $59.30 \pm 19.91$ & $57.91 \pm 12.79$ & $64.17 \pm 12.69$ & $0.040^{\dagger}$ \\
\hline \multicolumn{5}{|l|}{ Sex } \\
\hline Female & $56(53.8 \%)$ & $45(80.4 \%)$ & $11(19.6 \%)$ & \multirow[t]{2}{*}{$0.512^{\ddagger}$} \\
\hline Male & $48(46.2 \%)$ & $36(75.0 \%)$ & $12(25.0 \%)$ & \\
\hline \multicolumn{5}{|l|}{ Risk factors } \\
\hline Hypertension & $79(76.0 \%)$ & $63(79.7 \%)$ & $16(20.3 \%)$ & $0.480^{\ddagger}$ \\
\hline Diabetes mellitus & $17(16.3 \%)$ & $12(70.6 \%)$ & $5(29.4 \%)$ & $0.430^{*}$ \\
\hline Obesitya & $51(49.0 \%)$ & $41(80.4 \%)$ & $10(19.6 \%)$ & $0.546^{\ddagger}$ \\
\hline $\mathrm{IHD}$ & $2(1.9 \%)$ & $1(50.0 \%)$ & $1(50.0 \%)$ & $0.368^{*}$ \\
\hline Smoking & $38(36.5 \%)$ & $28(34.6 \%)$ & $10(43.5 \%)$ & $0.289^{\ddagger}$ \\
\hline Tobacco leaf use & $29(27.9 \%)$ & $23(28.4 \%)$ & $6(26.1 \%)$ & $0.998^{\ddagger}$ \\
\hline Alcohol drinking & $2(1.9 \%)$ & $1(50.0 \%)$ & $1(50.0 \%)$ & $0.368^{*}$ \\
\hline \multicolumn{5}{|l|}{ GCS } \\
\hline 13-15 & $54(51.9 \%)$ & $51(94.4 \%)$ & $3(5.6 \%)$ & \multirow[t]{3}{*}{$<0.001^{*}$} \\
\hline $5-12$ & $46(44.2 \%)$ & $30(65.2 \%)$ & $16(34.8 \%)$ & \\
\hline $3-4$ & $4(3.8 \%)$ & $0(0 \%)$ & $4(100 \%)$ & \\
\hline \multicolumn{5}{|l|}{ Hematoma volume } \\
\hline$<30 \mathrm{cc}$ & $75(72.1 \%)$ & $66(88.0 \%)$ & $9(12.0 \%)$ & \multirow[t]{2}{*}{$<0.001^{\ddagger}$} \\
\hline e"30 cc & $29(27.9 \%)$ & $15(51.7 \%)$ & $14(48.3 \%)$ & \\
\hline \multicolumn{5}{|l|}{ Location } \\
\hline Supratentorial & $95(91.3 \%)$ & $75(78.9 \%)$ & $20(21.1 \%)$ & \multirow[t]{2}{*}{$0.402^{*}$} \\
\hline Infratentorial & $9(8.7 \%)$ & $6(66.7 \%)$ & $3(33.3 \%)$ & \\
\hline $\mathrm{IVH}^{\mathrm{a}}$ & $45(43.3 \%)$ & $27(60.0 \%)$ & $18(40.0 \%)$ & $<0.001^{*}$ \\
\hline Hydrocephalus & $9(8.7 \%)$ & $3(33.3 \%)$ & $6(66.7 \%)$ & $0.003^{*}$ \\
\hline \multicolumn{5}{|c|}{$\begin{array}{l}\text { Data are expressed as frequency (percentage) if not mentioned otherwise. }{ }^{*} p \text { value derived from Fischer's exact test; }{ }^{\ddagger} p \text { valu } \\
\text { derived from Chi-square test; }{ }^{\dagger} p \text { value derived from Student's t-test; Significant values are in bold face.IVH; Intraventricula } \\
\text { hemorrhage. }\end{array}$} \\
\hline \multicolumn{5}{|c|}{$\begin{array}{l}\text { Table-II } \\
\text { 30-days mortality rate for the Entire Cohort of } 104 \text { patients with ICH and Stratified by ICH Score }\end{array}$} \\
\hline $\mathrm{ICH}$ score & $\mathrm{n}(\%)$ & $\begin{array}{r}\text { Case fatali } \\
\text { 30-day, }\end{array}$ & & $\begin{array}{l}\text { 95\% Confidence } \\
\text { intervals }\end{array}$ \\
\hline 0 & $27(25.9 \%)$ & $0\left(0^{\circ}\right.$ & & $0-0$ \\
\hline 1 & $34(32.7 \%)$ & $2(5.9$ & & $0.02-13.82$ \\
\hline 2 & $21(20.2 \%)$ & $7(33$. & & $13.14-53.46$ \\
\hline 3 & $13(12.5 \%)$ & $6(46$. & & $19.09-73.30$ \\
\hline 4 & $9(8.7 \%)$ & $8(88$. & & $68.38-100$ \\
\hline Entire cohort & $104(100 \%)$ & $23(22$ & & 14.13-30.07 \\
\hline
\end{tabular}


Table-III

Multivariate logistic regression analysis of predictive 30-days mortality in 104 patients with ICH

\begin{tabular}{lccccc}
\hline Variables & $\beta$ & Odds ratio (OR) & \multicolumn{2}{c}{$95 \%$ Cl of OR } & P value \\
\cline { 4 - 5 } & & & Lower & Upper & \\
\hline Age & 0.037 & 1.04 & 0.98 & 1.09 & 0.196 \\
GCS & -0.398 & 0.67 & 0.52 & 0.86 & 0.002 \\
Hematoma volume $(\geq 30 \mathrm{cc})$ & 1.565 & 4.78 & 1.23 & 18.57 & 0.024 \\
IVH & 0.084 & 1.09 & 0.24 & 4.98 & 0.914 \\
Hydrocephalus & 2.111 & 8.25 & 1.11 & 61.24 & 0.039 \\
\hline
\end{tabular}

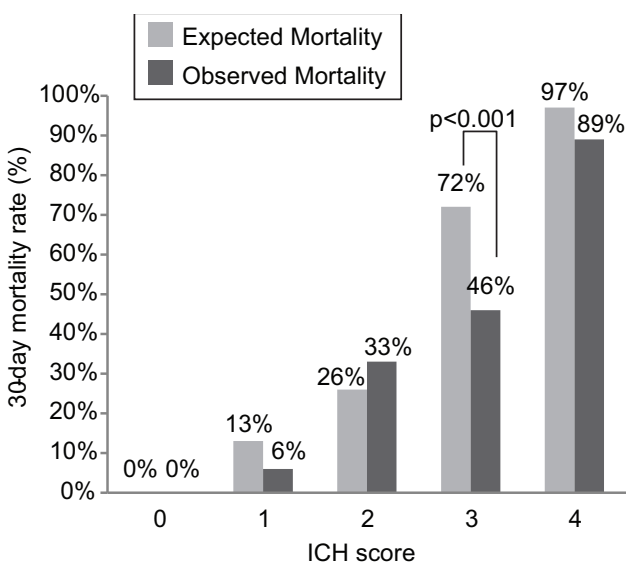

Fig.-1: 30-day mortality rate by presenting ICH score (Blue bars show expected mortality rate based on the original ICH score. Red bars show observed mortality rates in our patient cohort. Significant differences were seen between patients with ICH scores of 3).

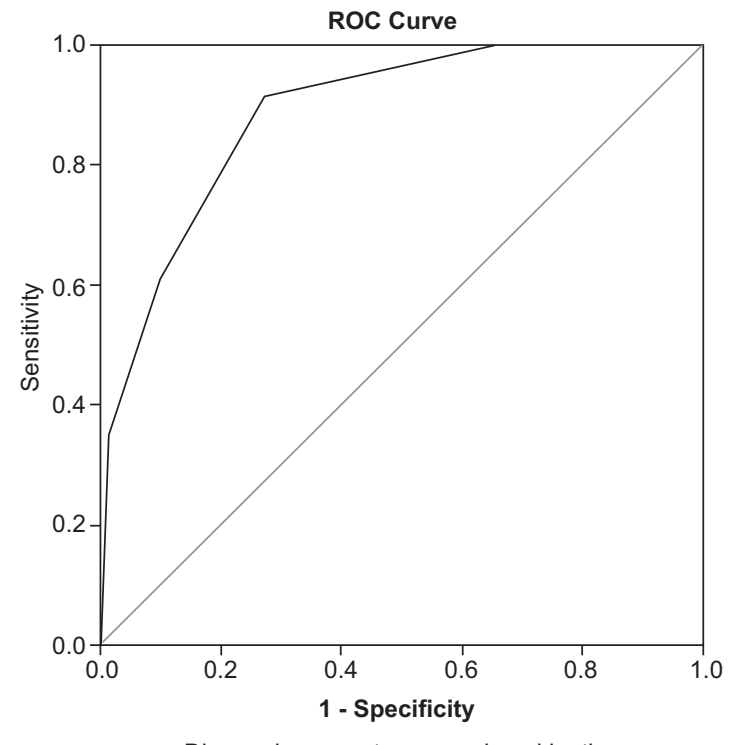

Diagonal segments are produced by ties

Fig.-2: Receiver operating characteristic (ROC) curve for ICH score in predicting 30-day mortality outcome.

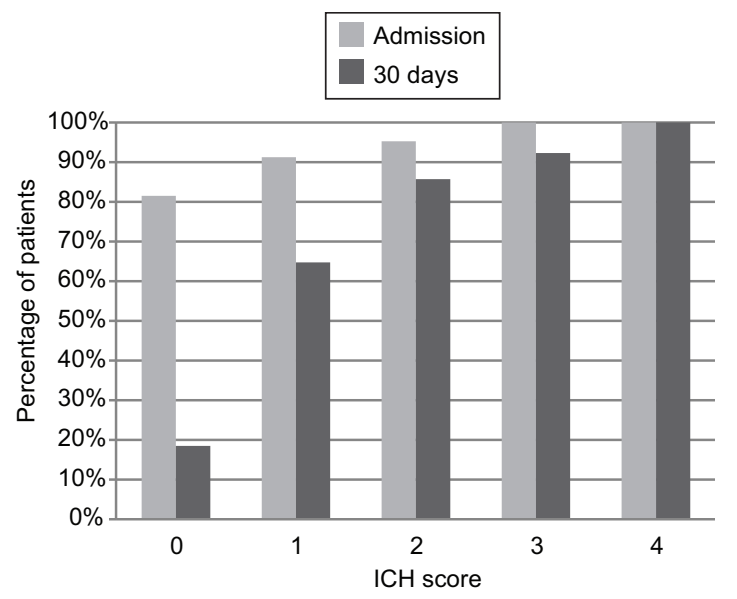

Fig.-3: The ICH score and proportion of patients with modified Rankin score of e"4 at admission and one month after discharge.

hematoma volume ( $\geq 30 \mathrm{cc}$ ), and the presence of hydrocephalous were independent predictors of 30 daymortality $(p=0.002, p=0.024$ and $p=0.039$ respectively).

\section{Discussion:}

In this prospective study in Bangladesh, we have demonstrated that the $\mathrm{ICH}$ score is a valid prognostic indicator of 30-day case fatality. The overall 30-day mortality rate in the present cohort was $22.1 \%$. When stratified by $\mathrm{ICH}$ scores, the mortality rate was significantly lower than the predicted mortality, which has been previously reported, in patients with $\mathrm{ICH}$ score 3 . The observed mortality rate in the present study was similar to that predicted in Hemphill's ICH score for the other $\mathrm{ICH}$ scores $^{8}$. Historically quoted 30day mortality rates of $72 \%$ for scores of 3 were based on a sample size of 32 patients for ICH score of 3 in the original cohort where the $\mathrm{ICH}$ score was 
developed $^{8}$. In our patient population, the total number of patients with an $\mathrm{ICH}$ Score of 3 was only 13 , of which 6 died (mortality rate of $46.2 \%$ ). Difference in the sample sizes might be responsible for these differences in the observed and expected mortality rate between original and present study cohort.

The pattern and demography of spontaneous $\mathrm{ICH}$ in Bangladesh is different from the western world but quite similar to our neighboring country India. The mean age of the patients in the present study was $59.30( \pm 19.91)$ years, which is predominantly younger in comparison to the western population where the mean age was $70-79$ years $8,9,15$. However, most of the available studies from Bangladesh and India report mean ages of 55-65 years ${ }^{6,14,16}$. Only $10.6 \%$ patients were above the age of 80 in the present study. The United Nations report states that the average life expectancy of a Bangladeshi at birth is 72.72 years ${ }^{17}$. Thus, most of our population fail to live beyond the age of 80 which is one of the cutoff criteria for the existing $\mathrm{ICH}$ scoring system. This was evident from our observation that none of the patients in this study group had an $\mathrm{ICH}$ score of 5 . In the present study male to female representation was almost equal (46.2\% versus $53.8 \%$ ). Several other studies also observed such non-significant gender differences ${ }^{14,18}$. Hypertension was the most prevalent risk factor in the current cohort $(76 \%)$ followed by obesity (49\%). IHD, smoking, and alcohol abuse were less prominent risk factors in the present study. This pattern was more or less similar to the findings from the study in and around our country ${ }^{19,20}$.

The 30 day mortality of patients with spontaneous $\mathrm{ICH}$ has been reported as ranging from 25 to $52 \% 10,21,22$. The low rate at $22.1 \%$ in our study might be explained by our exclusion criteria. Patients with an initial absence of brainstem reflexes in whom the non-treatment concept was clear were not included in the study group. Concerning the short term outcome (after 30-days), $21(20.19 \%)$ patients had mRSscore d"2 (slight disability to no symptom at all) and 66 (63.46\%) had $\mathrm{mRS}$ score $\geq 4$ (moderately severe disability to dead). In a meta analysis, Van Asch et al. presented a functional outcome with independency rates of between 12 and $39 \%$ corresponding to the findings of present study ${ }^{23}$.

Multivariate analysis of the components of $\mathrm{ICH}$ score in our study subjects revealed that GCS and hematoma volume (e" $30 \mathrm{cc})$ were strong predictors of 30-day mortality. However, the infratentorial origin of hemorrhage and IVH despite having high odds for death was not signiûcantly associated with the mortality prediction, which is in contradiction with the previous studies ${ }^{8,24}$. This discordance could possibly be due to very small number of patients having infratentorial hemorrhage $(8.7 \%$ infratentorial versus $91.3 \%$ supratentorial), which could not reach statistical signiûcance. Most of the patients with IVH in the present study had associated hematoma volume of e"30 cc. So, the IVH was not revealed as an independent predictor of 30-day mortality though this variable had highly significant association $(p<0.001)$ with 30 -day mortality in univariate analysis. Age 80 years or older was an independent predictor of mortality in the original study of the $\mathrm{ICH}$ score ${ }^{8}$. The lack of association between age of 80 years or older and mortality in the present study may be due to the small number $(11 / 104 ; 10.6 \%)$ of patients older than 80 years.

The present study also demonstrated that, the radiological feature hydrocephalus was an independent predictor of 30-day mortality. Diringer et al. demonstrated for the first time the impact of hydrocephalus on outcome from $\mathrm{ICH}^{25}$. Hydrocephalus was associated with a considerably higher mortality and fewer patients being discharged to home in their study. In agreement to our study, univariate and multivariate analyses indicate that hydrocephalus was an independent predictor of outcome in that study ${ }^{25}$. Later on, this factor is validated by other study ${ }^{6}$.

The Hemphill ICH score has been validated numerous times in the literature, with a pooled AUC of 0.8 in an international meta-analysis ${ }^{26}$. In the present study the AUC for the $\mathrm{ICH}$ score was 0.886 (95\% Cl: 0.816-0.956; $p<.001$ ) which was consistence with other studies ${ }^{26}$.

The results of the present study also support the validity of the $\mathrm{ICH}$ score in predicting early functional outcome in addition to mortality. This is consistent 
with the study of Jamoraet al ${ }^{11}$. But in disagreement with the study that have evaluated outcome too early at discharge without accounting for the eventual improvement in function over time ${ }^{12}$.

Strength and limitations: The strengths of our study include the prospective nature of the data collection and the blinding of image analysis and prognostic score determination to survival status. ICH grading scores are not routinely used for clinical care at our hospital and were determined retrospectively for this study, thus preventing them from influencing care decisions and, hence, prognosis. We were able to ascertain the outcome status of almost all of the patients with otherwise complete data and only 1 out of $105(<1 \%)$ could not be traced. However, lack of long-term follow-up of patients after discharge from the hospital and sample from a single hospital were some of the limitations of the present study. Moreover, we could not establish the true strength of association of infratentorial origin of hemorrhage and age e"80years because of the small number of subjects in these respective categories.

Conclusion:In conclusion, our study has demonstrated that the $\mathrm{ICH}$ score is a prognostic indicator of $\mathrm{ICH}$ for both30-day mortality and 30day functional outcome among hospitalized patients in Bangladesh.A numerical scoring system like $\mathrm{ICH}$ score can improve the consistency among the physicians regarding severity of $\mathrm{ICH}$ which in turn can help during counseling the caregivers.

Recommendations:As the ICH score was observed to have a good discriminative power for predicting 30-day mortality in patients with $\mathrm{ICH}$, present study recommended routine assessment of $\mathrm{ICH}$ scores in patients with $\mathrm{ICH}$ in admission. However, results of the current study need to be confirmed by further prospective, multicenter studies with larger sample size.

\section{Acknowledgement:}

Dr. Pradip Kumar Kayasthagir, Dr. Md. Mahabubul Alam Khandker, Dr. S A M Masihuzzaman (Alpha), Dr. TouhidurRahman, Dr. Zaman Ahmed, Dr. AnwarulKibria, Dr. AkramulAzam, Dr. FaridUddin Ahmed, Dr. Sanjay Saha.

\section{Contribution of authors:}

MSE: Conception, designing, data collection, data analysis, manuscript drafting \& final approval
$\mathrm{MH}$ : Conception, Manuscript drafting \& final approval

SM: Manuscript drafting \& final approval

Conflict of Interests: The authors declare no conflict of interest in this study.

\section{References:}

1. An SJ, Kim TJ, Yoon BW. Epidemiology, Risk Factors, and Clinical Features of Intracerebral Hemorrhage: An Update. J Stroke. 2017;19(1):3-10.

2. O'Donnell MJ, Xavier D, Liu L, Zhang H, Chin $\mathrm{SL}$, Rao-Melacini $\mathrm{P}$, et al. Risk factors for ischemic and intracerebral hemorrhagic stroke in 22 countries (the INTERSTROKE study): a case-control study. Lancet. 2010;376(9735):112-23.

3. Qureshi Al, Tuhrim S, Broderick JP, Batjer HH, Hondo H, Hanley DF. Spontaneous intracerebral hemorrhage. N Engl J Med. 2001;344(19):1450-60.

4. Fogelholm R, Murros K, Rissanen A, Avikainen $\mathrm{S}$. Long term survival after primary intracerebralhaemorrhage: a retrospective population based study. J NeurolNeurosurg Psychiatry. 2005;76(11):1534-38.

5. Jiang B, Wang WZ, Chen $\mathrm{H}$, Hong Z, Yang QD, Wu SP, et al. Incidence and trends of stroke and its subtypes in China: results from three large cities. Stroke. 2006;37(1):63-8.

6. Hegde A, Menon G. Modifying the Intracerebral Hemorrhage Score to Suit the Needs of the Developing World. Ann Indian Acad Neurol. 2018;21(4):270-74.

7. Ruiz-Sandoval JL, Chiquete E, RomeroVargas S, Padilla-Martínez JJ, GonzálezCornejo S. Grading scale for prediction of outcome in primary intracerebral hemorrhages. Stroke. 2007;38(5):1641-44.

8. Hemphill JC 3rd, Bonovich DC, Besmertis L, Manley GT, Johnston SC. The ICH score: a simple, reliable grading scale for intracerebral hemorrhage. Stroke. 2001; 32(4):891-97.

9. Clarke JL, Johnston SC, Farrant M, Bernstein R, Tong D, Hemphill JC 3rd. External validation of the $\mathrm{ICH}$ score. Neurocrit Care. 2004;1(1):53-60. 
10. Godoy DA, Boccio A. ICH score in a rural village in the republic of Argentina. Stroke.2003; 34(9):e150-51.

11. Jamora RD, Kishi-Generao EM Jr, Bitanga ES, Gan RN, Apaga NE, San Jose MC. The $\mathrm{ICH}$ score: predicting mortality and functional outcome in an Asian population. Stroke. 2003; 34(1):6-7.

12. Fernandes $H$, Gregson $B A$, Siddique MS, Mendelow AD. Testing the $\mathrm{ICH}$ score. Stroke.2002; 33(6):1455-56.

13. Abdallah A, Chang JL, O'Carroll CB, Okello $S$, Olum $S$, Acan $M$, et al. Validation of the Intracerebral Hemorrhage Score in Uganda. Stroke. 2018;49(12):3063-66.

14. Pan K, Panwar A, Roy U, Das BK. A Comparison of the Intracerebral Hemorrhage Score and the Acute Physiology and Chronic Health Evaluation II Score for 30-Day Mortality Prediction in Spontaneous Intracerebral Hemorrhage. Journal of Stroke and Cerebrovascular Diseases. 2017; 26(11): 2563-69.

15. Masotti L, Lorenzini G, Di Napoli M, Godoy DA. Prognostic ability of four clinical grading scores in spontaneous intracerebral hemorrhage. NeurologicaBelgica.2016;117(1): 325-27.

16. Rashid MM, Islam MA, Sagir $G$, Islam MR, Khan MA, Moslehuddin F, et al. Clinical Profiles of Spontaneous Intracerebral Haemorrhage Patients: Experience of 100 Cases in Dhaka City. Journal of Current and Advance Medical Research.2018; 5(2):64-7.

17. United Nations - World Population Prospects. Bangladesh Life Expectancy 1950-2019. Available at: <a href='https:// www.macrotrends.net/countries/BGD/ bangladesh/life-expectancy'>Bangladesh Life Expectancy 1950-2020</a>. Retrieved 202003-15.

18. Suthar NN, Patel KL, Saparia C, Parikh AP. Study of clinical and radiological profile and outcome in patients of intracranial hemorrhage. Annals of African medicine. 2016; 15(2): 69-77.

19. Safatli DA, Günther A, Schlattmann $P$, Schwarz F, Kalff R, Ewald C. Predictors of 30-day mortality in patients with spontaneous primary intracerebral hemorrhage. Surgical neurology international.2016; 7(Suppl 18): S510-S517. doi:10.4103/2152-7806.187493.

20. Hussain ME, Mohammad QD, Habib M, Hoque MA, Alam MB, Yusuf MA. Aetiology of Spontaneous Intracerebral Haemorrhage in Young Adults Admitted at a Tertiary Care Hospital in Dhaka. American Journal of Neuroscience.2015; 6(2): 20-25

21. Bhatia R, Kumar G, Padma M, Prasad K, Singh $\mathrm{H}$, Singh $\mathrm{S}$, et al. A prospective study of in-hospital mortality and discharge outcome in spontaneous intracerebral hemorrhage. Neurology India.2013; 61(3): 244.

22. Sacco S, Marini C, Toni D, Olivieri L, Carolei A. Incidence and 10-Year Survival of Intracerebral Hemorrhage in a PopulationBased Registry. Stroke.2008;40(2), 394-99.

23. Van Asch CJ, Luitse MJ, Rinkel GJ, van der Tweel I, Algra A, Klijn CJ. Incidence, case fatality, and functional outcome of intracerebral hemorrhage over time, according to age, sex, and ethnic origin: a systematic review and meta-analysis. The Lancet Neurology.2010; 9(2): 167-76.

24. Muengtaweepongsa S, Seamhan B. Predicting mortality rate with $\mathrm{ICH}$ score in Thai intracerebral hemorrhage patients. Neurol Asia.2013; 18:131-135.

25. Diringer MN, Edwards DF, Zazulia AR. Hydrocephalus: A Previously Unrecognized Predictor of Poor Outcome from Supratentorial Intracerebral Hemorrhage. Stroke. 1998; 29(7): 1352-57.

26. Mattishent K, Kwok CS, Ashkir L, Pelpola K, Myint PK, Loke YK. Prognostic tools for early mortality in hemorrhagic stroke: systematic review and meta-analysis. J Clin Neurol.2015;11(4):339-48. 